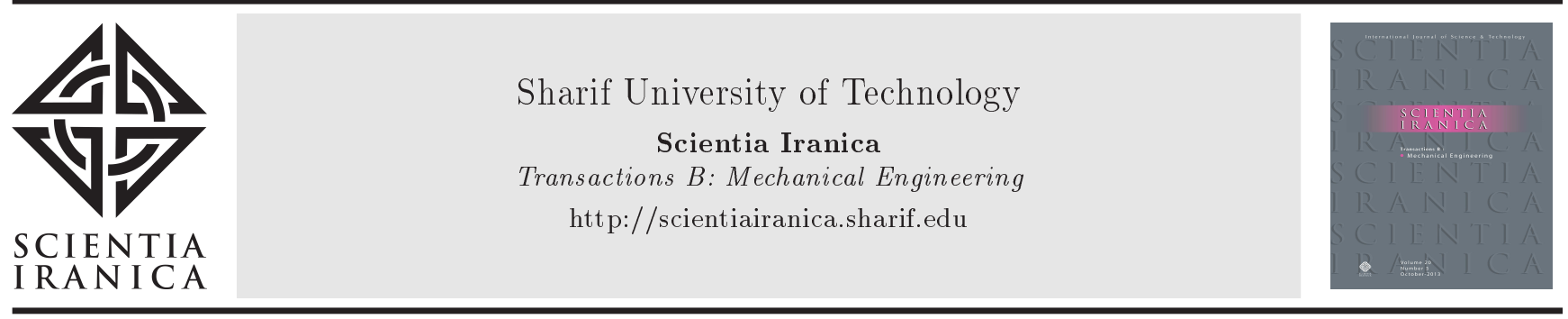

\title{
Studying buckling of composite rods made of hybrid carbon fiber/carbon nanotube-reinforced polyimide using multi-scale FEM
}

\author{
M. Ahmadia, R. Ansaria ${ }^{a}$, and H. Rouhi ${ }^{b, *}$ \\ a. Department of Mechanical Engineering, University of Guilan, Rasht, P.O. Box 3756, Iran. \\ b. Department of Engineering Science, Faculty of Technology and Engineering, East of Guilan, University of Guilan, P.C. \\ 44891-63157, Rudsar-Vajargah, Iran.
}

Received 7 December 2017; received in revised form 9 September 2018; accepted 3 November 2018

KEYWORDS
Multiscale composite
rod;
Hybrid carbon
nanotube/carbon fiber
reinforcement;
Polyimide;
Buckling;
Finite element
method.

\section{Introduction}

Hybrid composite materials have been the focus of several research works in recent years [1-7]. This attention is mainly given to a wide range of possibilities available to modify the properties of such materials on different length scales. In particular, polymer matrix composites reinforced with Carbon Nanotubes (CNTs) and Carbon Fibers (CFs) have attracted much attention from the research community due to their

\footnotetext{
*. Corresponding author. Tel. /Fax: +981342688447 E-mail addresses: masoud_ahmadi_pr@yahoo.com (M. Ahmadi); r_ansari@guilan.ac.ir (R. Ansari); h_rouhi@guilan.ac.ir (H. Rouhi)
}

excellent mechanical and electrical properties together with multifunctionality. For example, CNT/CF/epoxy composites indicated $\sim 30 \%$ enhancement of the interlaminar shear strength in comparison with that of CF/epoxy composites without CNTs and demonstrated considerably improved out-of-plane electrical conductivity [1]. Alipour Skandani and Al-Haik [5] revealed that the surface grown CNTs could enhance the CF-reinforced composite resistance to viscoplastic deformation. Pal and Kumar [6] showed that, even at low CF content, dispersing CNTs in the CF-polymer composite significantly improved the effective electrical conductivity and electrical percolation threshold of the resulting composite. The properties and performance of CNT-reinforced composites are dependent on different parameters. Synthesizing strategy, morphology of CNTs, type of matrix (e.g., metal, polymer, etc.), 
dispersion of CNTs, and interfacial reactions between CNTs and matrix can be mentioned as some examples. The reader is referred to [8] for more details.

Up to now, many micromechanical models have been developed to estimate the mechanical properties of CNT-reinforced composites [9-15]. Moreover, there are some research works in which the mechanical behaviors (e.g., vibration, buckling, and bending) of structural elements made of nanocomposites have been studied [16-32].

Since the lattice structure of CNTs is not incorporated into the micromechanical models, the direct application of continuum micromechanical models may lead to inaccurate results in the analysis of CNT-reinforced composites [33]. Furthermore, $\mathrm{CNT} /$ polymer matrix interphase region is one of the most important factors in the analysis of reinforced polymers with CNTs [34]. The interphase is formed by non-bonded van der Waals interaction between the CNT and the surrounding matrix. Therefore, multiscale modeling approaches to the coupled micro- and nano-scale effects have been proposed in a number of studies [35-43].

Moreover, there are some size-dependent generalized continuum theories to capture small-scale effects. The nonlocal, strain gradient, and couple stress theories are well-known non-classical elasticity theories capable of considering size influences on micro and nano scales. On the basis of nonlocal elasticity theory, the stress tensor at a reference point in a body depends on the strain tensor not only at that point but also at all other points of the body. The nonlocal parameter of this theory can be determined based on experimental data or results of atomistic approaches like molecular dynamics simulations. The nonlocal theory has been applied to various problems such as buckling of microtubules and boron-nitride nanotubes embedded in an elastic medium [44,45] and bending/buckling/free vibration analyses of nanobeams $[46,47]$. The reader is also referred to [48-52] as some examples for the applications of strain gradient and couple stress theories.

As cited earlier, there are some papers on the finite element multi-scale modeling of structural elements made of nanocomposites. However, to the authors' knowledge, the buckling behavior of rods made of CNT/CF-reinforced polyimide considering coupled effects of micro and nano scales based on a finite element approach has not been investigated yet. Therefore, in the present paper, the multi-scale buckling analysis of composite rods made of CNT/CF-reinforced polyimide is presented by employing the Finite Element Method (FEM). To this end, the elastic properties of CNT/CF-RP including Young's modulus and Poisson's ratio are first determined using a dual-step procedure. In the first step, CNTs with three values of volume fraction $(1 \%, 3 \%$, and $5 \%$ ) are randomly dispersed into the polymer matrix (polyimide). In the selected Representative Volume Element (RVE), the interphase region between CNTs and the polymer matrix is taken into account. Then, a random distribution of CFs into the CNT-reinforced polymer is modeled according to six cases of hybrid CNT/CF reinforcement. The elastic properties of the composite are calculated with and without considering the interphase influence. After that, the axial buckling of rods made of $\mathrm{CNT} / \mathrm{CF}$ $\mathrm{RP}$ with circular and square cross-sections is analyzed. The analysis is performed via two models: a $3 \mathrm{D}$ brick model and a 2D beam model. The effects of some important factors including interphase, volume fraction of $\mathrm{CNT} / \mathrm{CF}$, and size on the critical buckling loads are investigated. Moreover, a comparison is made between the predictions of brick and beam models.

\section{Dual-step multi-scale finite element modeling}

In order to estimate the elastic constants of polyimide reinforced by CFs and CNTs, a dual-step procedure is adopted herein [38]. In the first step, CNTs are dispersed into the polymer matrix (polyimide) with three volume fractions including $1 \%, 3 \%$, and $5 \%$. The RVE model of this step is observed in Figure 1. The dispersion of CNTs is considered to be random from the viewpoint of orientation and coordinates. In addition, they are dispersed almost homogenously without aggregation. The RVE consists of three phases: CNTs, polymer matrix, and interphase. The interphase is formed due to the non-bonded van der Waals interaction between the CNT and the surrounding matrix. It is modeled as a layer developed around the CNT. Shen

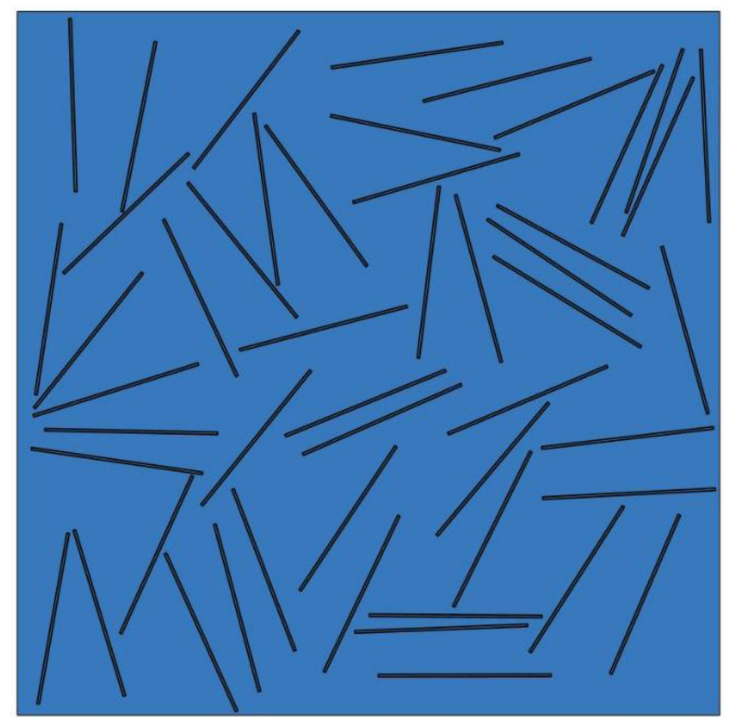

Figure 1. Representative Volume Element (RVE) model of composite with random Carbon Nanotube (CNT) distribution. 


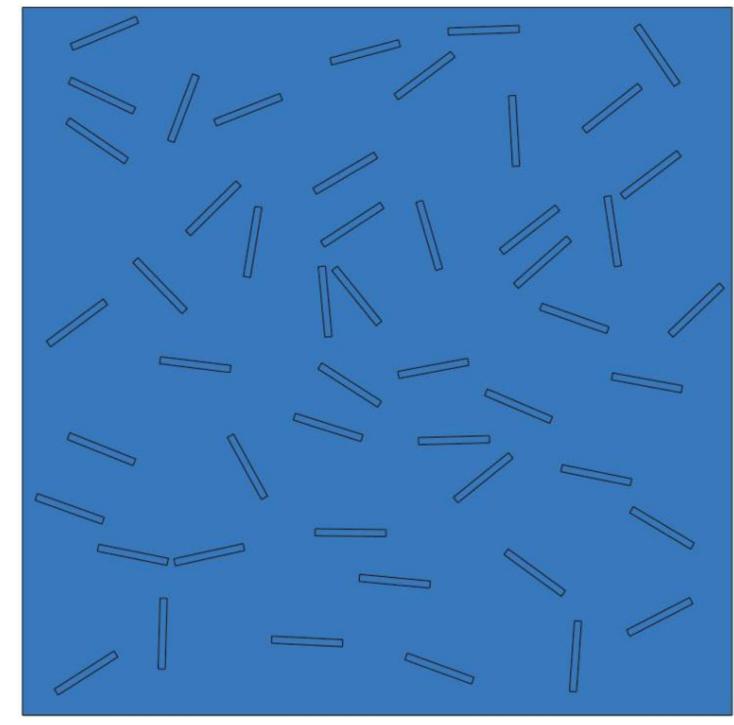

Figure 2. Representative Volume Element (RVE) model of composite with random Carbon Fiber (CF) distribution.

and $\mathrm{Li}[53,54]$ showed that CNTs were transversely isotropic materials. Consequently, CNTs are modeled as transversely isotropic materials in the present finite element modeling. Further, the polymer matrix and interphase are considered as isotropic.

In the next step, CFs are distributed in the CNT-Reinforced Polyimide (CNT-RP), considered to be homogenous materials with the properties that were evaluated in the first step. Six cases as follows are studied for the hybrid reinforcement:

- $0.95 \% \mathrm{CNT}+5 \% \mathrm{CF}+$ Polyimide,

- $2.85 \% \mathrm{CNT}+5 \% \mathrm{CF}+$ Polyimide,

- $4.75 \% \mathrm{CNT}+5 \% \mathrm{CF}+$ Polyimide,

- $0.9 \% \mathrm{CNT}+10 \% \mathrm{CF}+$ Polyimide,

- $2.7 \% \mathrm{CNT}+10 \% \mathrm{CF}+$ Polyimide,

- $4.5 \% \mathrm{CNT}+10 \% \mathrm{CF}+$ Polyimide.

The RVE model of nanocomposite with the random dispersion of CFs is indicated in Figure 2. Similar to CNTs, CFs are assumed to be transversely isotropic. The Python programming language is utilized to create randomly distributed/oriented CNTs/CFs inside the RVE. It should be noted that the positions of CNTs/CFs are determined such that no overlapping occurs between them.

Figure 3 shows examples of meshed RVEs. Figure 4 represents the loading and boundary conditions of RVE to obtain Young's modulus. It is assumed that the effective properties of the nanocomposite are similar to those of RVE. By measuring the fixed boundary reaction force and calculating stress value $(\sigma)$, the equivalent elastic modulus $(E)$ of nanocomposite RVE is obtained based on Hooke's law as follows:

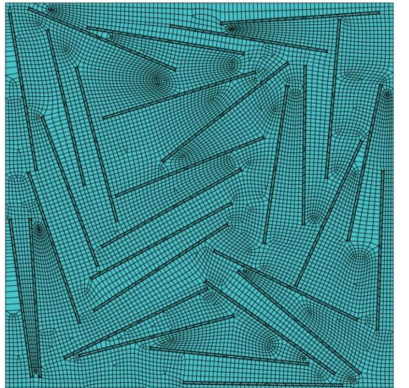

(a)

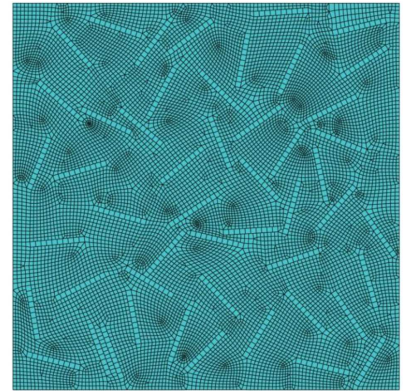

(b)
Figure 3. Examples of meshed Representative Volume Elements (RVEs) for (a) CNT-reinforced polyimide, and (b) Carbon fiber-reinforced polyimide.

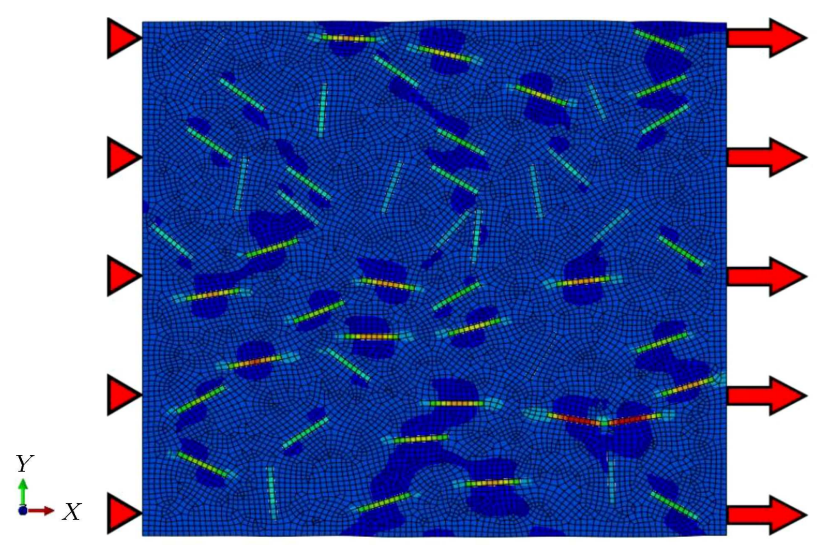

Figure 4. Stress distribution contour (tensile test for obtaining elastic modulus of nanocomposite).

$$
E=\frac{\sigma}{\varepsilon}
$$

where $\varepsilon$ is the RVE strain in the load direction. Poisson's ratio is also defined as the ratio of transverse strain to axial strain. It should be noted that the results are obtained for each reinforcement type using the average values of three analyses with various random microstructures in order to reduce the effect of chance on the results because of random dispersion. Besides, the present calculations reveal that there is a negligible difference between the results of $2 \mathrm{D}$ and $3 \mathrm{D}$ RVEs. Hence, 2D RVEs are used instead of 3D ones due to the high computational cost of $3 \mathrm{D}$ models.

After calculating Young's modulus and Poisson's ratio of CNT/CF-RP for various reinforcement types with and without the interphase influence, the buckling analysis of rods with circular and square cross-sections is performed. The finite element modeling is performed using two models: a 3D brick model and a 2D beam model, as shown in Figure 5. On a micro scale, an 8node biquadratic plane stress quadrilateral element is used. Moreover, on a macro scale, a 3-node quadratic beam in space is used for the $2 \mathrm{D}$ beam model, and a 20-node quadratic brick is used for the 3D brick model. 


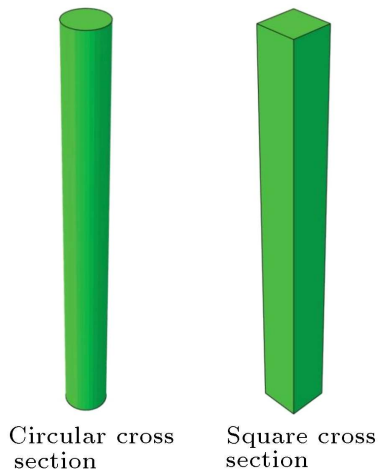

(a)

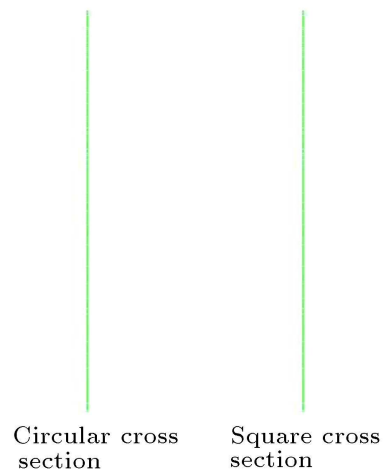

(b)
Figure 5. (a) 3D brick and (b) $2 \mathrm{D}$ beam models for the buckling analysis of rods.

\section{Results and discussion}

First, in order to validate the proposed multi-scale FEM, the present results of Young's modulus of polypropylene reinforced with randomly oriented CNTs are compared with the experimental results given in [55]. Table 1 shows the normalized Young's modulus of CNT-reinforced polypropylene for different volume fractions of CNT. It is seen that the present results are in good agreement with those reported in [55].

The material properties of composite constituents are given in Table 2. In this table, longitudinal Young's modulus $\left(E_{L}\right)$, transverse Young's modulus $\left(E_{T}\right)$, longitudinal Poisson's ratio $\left(\nu_{L}\right)$, transverse Poisson's ratio $\left(\nu_{T}\right)$, longitudinal shear modulus $\left(G_{L}\right)$ and mass density $(\rho)$ of CNTs, interphase, CFs, and the polymer matrix are presented. The aspect ratio and diameter of CFs are selected as 10 and $10 \mu \mathrm{m}$, respectively. Moreover, the aspect ratio and diameter of CNTs are taken as 100 and $0.78 \mathrm{~nm}$, respectively. Moreover, the thickness of interphase is considered to be $0.3333 \mathrm{~nm}$.

Table 1. Dimensionless Young's modulus of CNT-reinforced polypropylene.

\begin{tabular}{|c|c|c|c|}
\hline $\begin{array}{l}\text { CNT }^{a} \text { volume } \\
\text { fraction }(\%)\end{array}$ & $\begin{array}{c}\text { Present } \\
\text { FEM }^{\mathrm{b}}\end{array}$ & $\begin{array}{c}\text { Experiment } \\
{[55]}\end{array}$ & $\begin{array}{r}\text { Difference } \\
\text { percentage }\end{array}$ \\
\hline 1.6 & 1.161 & 1.19 & 2.4 \\
\hline 3.2 & 1.319 & 1.29 & 2.2 \\
\hline 4.8 & 1.526 & 1.39 & 9.8 \\
\hline
\end{tabular}

${ }^{a}$ CNT: Carbon nanotube; ${ }^{b}$ FEM: Finite Element Method.
Table 3. Mesh convergence study in the case of $2.85 \%$ CNT $-5 \%$ CF-RP ${ }^{\mathrm{a}}$.

\begin{tabular}{ccc}
\hline No. of elements & $\boldsymbol{E}(\mathbf{G P a})$ & Error $(\%)$ \\
\hline 3933 & 7.0723 & 0.54 \\
6963 & 7.0568 & 0.32 \\
13808 & 7.0456 & 0.16 \\
22834 & 7.0407 & 0.09 \\
29953 & 7.0378 & 0.05 \\
43499 & 7.0365 & 0.03 \\
52276 & 7.0357 & 0.02 \\
68465 & 7.0346 & 0.00 \\
83270 & 7.0343 & 0.00 \\
129724 & 7.0343 & 0.00 \\
\hline
\end{tabular}

${ }^{a}$ CNT: Carbon Nanotube; CF: Carbon Fiber;

RP: Reinforced Polyimide.

To study the mesh convergence, as an example, Young's modulus of $2.85 \% \mathrm{CNT}-5 \% \mathrm{CF}-\mathrm{RP}$ (without interphase) is computed with various mesh sizes, as shown in Table 3 . This table reveals a converged trend with a mesh size that is getting smaller. It is worth mentioning that the fining mesh is performed to reach a change smaller than $0.005 \%$ in the solution.

The values of equivalent Young's modulus, Poisson's ratio, and mass density of $\mathrm{CNT} / \mathrm{CF}$-reinforced polyimide for different volume fractions of $\mathrm{CNT} / \mathrm{CF}$ are tabulated in Table 4. The results of this table are generated with and without considering interphase in order to show such an effect. The elastic properties of pristine material (polyimide) are also given so as to study the effect of reinforcement. According to the results, given the interphase effect, Young's modulus is computed to be larger than that obtained without considering the interphase effect. For example, there is a $4.5 \%$ increase in the value of Young's modulus for $(4.75 \% \mathrm{CNT}+5 \% \mathrm{CF}+$ polyimide) when the interphase is considered.

As expected, reinforcing polyimide with $\mathrm{CNT} / \mathrm{CF}$ results in increasing the elastic modulus. For instance, when $5 \% \mathrm{CNT}$ is added to the polymer matrix, an $88 \%$ increase in the elastic modulus of the resulting composite material is observed. Further, the increase reaches $133 \%$ in the case of $(4.5 \% \mathrm{CNT}+10 \% \mathrm{CF}$ + polyimide). It is also observed that the effect of reinforcement on Poisson's ratio is insignificant.

Table 2. Material properties of Carbon Nanotube (CNT), interphase, Carbon Fiber (CF), and polyimide.

\begin{tabular}{ccccccc}
\hline Material & $\boldsymbol{E}_{\boldsymbol{L}}(\mathbf{G P a})$ & $\boldsymbol{E}_{\boldsymbol{T}}(\mathbf{G P a})$ & $\boldsymbol{\nu}_{\boldsymbol{L}}$ & $\boldsymbol{\nu}_{\boldsymbol{T}}$ & $\boldsymbol{G}_{\boldsymbol{L}}(\mathbf{G P a})$ & $\boldsymbol{\rho}\left(\mathbf{k g} / \mathbf{m}^{\mathbf{3}}\right)$ \\
\hline CNT [34] & 1382.5 & 645 & 0.272 & 0.2 & 1120 & 1300 \\
Interphase [34] & 19.29 & 19.29 & 0.34 & 0.34 & 7.2 & 1305 \\
CF [56] & 294 & 18.5 & 0.27 & 0.3 & 25 & 1760 \\
Polyimide [57] & 4.2 & 4.2 & 0.4 & 0.4 & 1.5 & 1310 \\
\hline
\end{tabular}


Table 4. Equivalent Young's modulus, Poisson's ratio, and mass density of polyimide reinforced with CNT/CF.

\begin{tabular}{lccc}
\hline Material & $\boldsymbol{E}(\mathbf{G P a})$ & $\boldsymbol{\nu}$ & $\boldsymbol{\rho}\left(\mathbf{k g} / \mathbf{m}^{\mathbf{3}}\right)$ \\
\hline Polyimide & 4.200 & 0.400 & 1310.00 \\
$1 \%$ CNT-RP (without interphase) & 4.786 & 0.399 & 1309.90 \\
1\% CNT-RP (with interphase) & 4.830 & 0.399 & 1309.86 \\
$3 \%$ CNT-RP (without interphase) & 6.223 & 0.398 & 1309.70 \\
$3 \%$ CNT-RP (with interphase) & 6.411 & 0.397 & 1309.57 \\
$5 \%$ CNT-RP (without interphase) & 7.554 & 0.396 & 1309.50 \\
$5 \%$ CNT-RP (with interphase) & 7.898 & 0.395 & 1309.29 \\
$0.95 \%$ CNT - 5\% CF-RP (without interphase) & 5.434 & 0.397 & 1332.41 \\
$0.95 \%$ CNT - 5\% CF-RP (with interphase) & 5.483 & 0.397 & 1332.36 \\
$2.85 \%$ CNT - 5\% CF-RP (without interphase) & 7.034 & 0.396 & 1332.22 \\
$2.85 \%$ CNT - 5\% CF-RP (with interphase) & 7.242 & 0.395 & 1332.09 \\
$4.75 \%$ CNT - 5\% CF-RP (without interphase) & 8.505 & 0.394 & 1332.03 \\
$4.75 \%$ CNT - 5\% CF-RP (with interphase) & 8.884 & 0.393 & 1331.82 \\
$0.9 \%$ CNT - 10\% CF-RP (without interphase) & 6.036 & 0.395 & 1354.91 \\
$0.9 \%$ CNT - 10\% CF-RP (with interphase) & 6.090 & 0.395 & 1354.87 \\
$2.7 \%$ CNT - 10\% CF-RP (without interphase) & 7.787 & 0.394 & 1354.73 \\
$2.7 \%$ CNT - 10\% CF-RP (with interphase) & 8.015 & 0.393 & 1354.61 \\
$4.5 \%$ CNT - 10\% CF-RP (without interphase) & 9.388 & 0.392 & 1354.55 \\
$4.5 \%$ CNT - 10\% CF-RP (with interphase) & 9.798 & 0.391 & 1354.36 \\
\hline
\end{tabular}

Note: CNT: Carbon Nanotube; CF: Carbon Fiber; RP: Reinforced Polyimide.

Now, the buckling results of composite rods made of $\mathrm{CNT} / \mathrm{CF}-\mathrm{RP}$ are given and discussed. It is considered that the rods are under an axial point load applied to the center of cross-sections (circular and square). Furthermore, the boundary condition of rods is assumed to be clamped-free.

In Table 5, the results of multi-scale FEM are compared with those obtained through Euler's formula. The critical load based on Euler's formula is given by:

$$
F_{c r}=\frac{\pi^{2} E I}{(K L)^{2}},
$$

where $E, I, L$, and $K$ denote elastic modulus, second moment of inertia of the cross-section, length, and effective length factor of the rod, respectively. The comparison is done for rods with both circular and square cross-sections using 3D brick and 2D beam models. In addition, various values of diameter are considered. It is observed that the finite element results agree well with the ones obtained based on Euler's formula.

Tables 6 and 7 show the critical buckling loads of rods made of different materials with circular and square cross-sections, respectively. The results of these tables are obtained by both brick and beam models. The effects of interphase, material, and geometrical properties on the buckling behavior of rods can be investigated herein. It is seen that with the hybrid $\mathrm{CNT} / \mathrm{CF}$ reinforcement at hand, the resistance of rods to applied axial load improves significantly. For example, for a cylindrical rod with a radius of $20 \mathrm{~mm}$, the critical buckling load increases by $123 \%$ when the material changes from polyimide to $(4.5 \% \mathrm{CNT}+10 \%$ $\mathrm{CF}+$ Polyimide).

Besides, the interphase effect on the calculated critical buckling loads is observed in Tables 6 and 7 .

Table 5. Comparison between the results of the present multi-scale Finite Element Method (FEM) and those of Euler's formula for the buckling of rods with circular and square cross-sections.

\begin{tabular}{|c|c|c|c|c|c|c|c|}
\hline \multicolumn{4}{|c|}{ Rods with circular cross section } & \multicolumn{4}{|c|}{ Rods with square cross section } \\
\hline$d$ & 3D brick & $2 \mathrm{D}$ beam & $\begin{array}{c}\text { Euler's critical } \\
\text { load }\end{array}$ & $d$ & 3D brick & $2 \mathrm{D}$ beam & $\begin{array}{c}\text { Euler's critical } \\
\text { load }\end{array}$ \\
\hline $2 \mathrm{~mm}$ & 13.057 & 13.013 & 13.023 & $2 \mathrm{~mm}$ & 1.3842 & 1.3814 & 1.3817 \\
\hline $5 \mathrm{~mm}$ & 509.53 & 506.24 & 508.70 & $4 \mathrm{~mm}$ & 22.176 & 22.084 & 22.108 \\
\hline $10 \mathrm{~mm}$ & 7804.8 & 7984.2 & 8139.148 & $10 \mathrm{~mm}$ & 862.14 & 857.78 & 863.59 \\
\hline
\end{tabular}


Table 6. Critical buckling load $(N)$ of rods with a circular cross-section.

\begin{tabular}{|c|c|c|c|c|c|}
\hline \multirow{3}{*}{ Material } & \multirow{3}{*}{$r(\mathbf{m m})$} & \multicolumn{2}{|c|}{ 3D brick } & \multicolumn{2}{|c|}{ 2D beam } \\
\hline & & Without & With & Without & With \\
\hline & & interphase & interphase & interphase & interphase \\
\hline \multirow[t]{5}{*}{ Polyimide } & 1 & \multicolumn{2}{|c|}{0.81499} & \multicolumn{2}{|c|}{0.81376} \\
\hline & 2 & \multicolumn{2}{|c|}{13.057} & \multicolumn{2}{|c|}{13.013} \\
\hline & 5 & \multicolumn{2}{|c|}{509.53} & \multicolumn{2}{|c|}{506.24} \\
\hline & 10 & \multicolumn{2}{|c|}{7804.8} & \multicolumn{2}{|c|}{7984.2} \\
\hline & 20 & \multicolumn{2}{|c|}{102384} & \multicolumn{2}{|c|}{120846} \\
\hline \multirow[t]{5}{*}{ 1\% CNT-RP } & 1 & 0.92870 & 0.93723 & 0.92730 & 0.93582 \\
\hline & 2 & 14.879 & 15.015 & 14.828 & 14.964 \\
\hline & 5 & 580.62 & 585.96 & 576.87 & 582.18 \\
\hline & 10 & 8893.7 & 8975.5 & 9098.2 & 9181.8 \\
\hline & 20 & 116669 & 117742 & 137706 & 138972 \\
\hline \multirow[t]{5}{*}{$3 \%$ CNT-RP } & 1 & 1.2075 & 1.2440 & 1.2057 & 1.2421 \\
\hline & 2 & 19.346 & 19.930 & 19.280 & 19.863 \\
\hline & 5 & 754.95 & 777.76 & 750.08 & 772.74 \\
\hline & 10 & 11564 & 11913 & 11830 & 12187 \\
\hline & 20 & 151699 & 156282 & 179053 & 184462 \\
\hline \multirow[t]{5}{*}{$5 \%$ CNT-RP } & 1 & 1.4658 & 1.5326 & 1.4636 & 1.5303 \\
\hline & 2 & 23.484 & 24.553 & 23.404 & 24.470 \\
\hline & 5 & 916.43 & 958.16 & 910.51 & 951.97 \\
\hline & 10 & 14037 & 14677 & 14360 & 15014 \\
\hline & 20 & 184145 & 192531 & 217349 & 227247 \\
\hline \multirow[t]{5}{*}{$0.95 \%$ CNT $-5 \%$ CF-RP } & 1 & 1.0544 & 1.0639 & 1.0528 & 1.0623 \\
\hline & 2 & 16.893 & 17.045 & 16.836 & 16.988 \\
\hline & 5 & 659.23 & 665.18 & 654.98 & 660.89 \\
\hline & 10 & 10098 & 10189 & 10330 & 10423 \\
\hline & 20 & 132466 & 133660 & 156351 & 157761 \\
\hline \multirow[t]{5}{*}{$2.85 \%$ CNT $-5 \%$ CF-RP } & 1 & 1.3649 & 1.4053 & 1.3628 & 1.4031 \\
\hline & 2 & 21.867 & 22.514 & 21.793 & 22.437 \\
\hline & 5 & 853.34 & 878.57 & 847.83 & 872.90 \\
\hline & 10 & 13071 & 13458 & 13372 & 13767 \\
\hline & 20 & 171469 & 176540 & 202388 & 208372 \\
\hline $4.75 \%$ CNT $-5 \%$ CF-RP & 1 & 1.6503 & 1.7239 & 1.6479 & 1.7213 \\
\hline & 2 & 26.440 & 27.618 & 26.350 & 27.525 \\
\hline & 5 & 1031.8 & 1077.8 & 1025.1 & 1070.8 \\
\hline & 10 & 15805 & 16509 & 16168 & 16888 \\
\hline & 20 & 207328 & 216567 & 244712 & 255617 \\
\hline $0.9 \%$ CNT $-10 \%$ CF-RP & 1 & 1.1713 & 1.1817 & 1.1695 & 1.1799 \\
\hline & 2 & 18.765 & 18.932 & 18.701 & 18.868 \\
\hline & 5 & 732.27 & 738.82 & 727.54 & 734.05 \\
\hline & 10 & 11217 & 11317 & 11474 & 11577 \\
\hline & 20 & 147141 & 148457 & 173672 & 175226 \\
\hline $2.7 \%$ CNT $-10 \%$ CF-RP & 1 & 1.5110 & 1.5553 & 1.5087 & 1.5529 \\
\hline & 2 & 24.208 & 24.917 & 24.126 & 24.832 \\
\hline & 5 & 944.69 & 972.35 & 938.59 & 966.08 \\
\hline & 10 & 14470 & 14894 & 14803 & 15237 \\
\hline & 20 & 189825 & 195383 & 224053 & 230614 \\
\hline $4.5 \%$ CNT $-10 \%$ CF-RP & 1 & 1.8217 & 1.9012 & 1.8189 & 1.8984 \\
\hline & 2 & 29.185 & 30.460 & 29.086 & 30.356 \\
\hline & 5 & 1138.9 & 1188.7 & 1131.6 & 1181.0 \\
\hline & 10 & 17445 & 18207 & 17847 & 18626 \\
\hline & 20 & 228853 & 238848 & 270119 & 281915 \\
\hline
\end{tabular}


Table 7. Critical buckling load $(N)$ of rods with a square cross-section.

\begin{tabular}{|c|c|c|c|c|c|}
\hline \multirow[b]{2}{*}{ Material } & \multirow[b]{2}{*}{$d(\mathrm{~mm})$} & \multicolumn{2}{|c|}{ 3D brick } & \multicolumn{2}{|c|}{ 2D beam } \\
\hline & & $\begin{array}{c}\text { Without } \\
\text { interphase }\end{array}$ & $\begin{array}{c}\text { With } \\
\text { interphase }\end{array}$ & $\begin{array}{c}\text { Without } \\
\text { interphase }\end{array}$ & $\begin{array}{c}\text { With } \\
\text { interphase }\end{array}$ \\
\hline \multirow[t]{5}{*}{ Polyimide } & 2 & \multicolumn{2}{|c|}{1.3842} & \multicolumn{2}{|c|}{1.3814} \\
\hline & 4 & \multicolumn{2}{|c|}{22.176} & \multicolumn{2}{|c|}{22.084} \\
\hline & 10 & \multicolumn{2}{|c|}{862.14} & \multicolumn{2}{|c|}{857.78} \\
\hline & 20 & \multicolumn{2}{|c|}{12851} & \multicolumn{2}{|c|}{13453} \\
\hline & 40 & \multicolumn{2}{|c|}{183615} & \multicolumn{2}{|c|}{199463} \\
\hline \multirow[t]{5}{*}{ 1\% CNT-RP } & 2 & 1.5773 & 1.5918 & 1.5741 & 1.5886 \\
\hline & 4 & 25.270 & 25.502 & 25.165 & 25.397 \\
\hline & 10 & 982.43 & 991.46 & 977.46 & 986.45 \\
\hline & 20 & 14644 & 14778 & 15330 & 15471 \\
\hline & 40 & 209234 & 211157 & 227293 & 229382 \\
\hline \multirow[t]{5}{*}{$3 \%$ CNT-RP } & 2 & 2.0509 & 2.1129 & 2.0467 & 2.1086 \\
\hline & 4 & 32.857 & 33.850 & 32.721 & 33.710 \\
\hline & 10 & 1277.4 & 1316.0 & 1270.9 & 1309.3 \\
\hline & 20 & 19041 & 19616 & 19933 & 20535 \\
\hline & 40 & 272056 & 280275 & 295538 & 304466 \\
\hline \multirow[t]{5}{*}{$5 \%$ CNT-RP } & 2 & 2.4896 & 2.6029 & 2.4845 & 2.5976 \\
\hline & 4 & 39.885 & 41.701 & 39.720 & 41.528 \\
\hline & 10 & 1550.6 & 1621.2 & 1542.8 & 1613.0 \\
\hline & 20 & 23113 & 24166 & 24196 & 25298 \\
\hline & 40 & 330245 & 345284 & 358748 & 375085 \\
\hline \multirow[t]{5}{*}{$0.95 \%$ CNT $-5 \%$ CF-RP } & 2 & 1.7909 & 1.8070 & 1.7872 & 1.8033 \\
\hline & 4 & 28.691 & 28.950 & 28.572 & 28.830 \\
\hline & 10 & 1115.4 & 1125.5 & 1109.8 & 1119.8 \\
\hline & 20 & 16627 & 16776 & 17406 & 17563 \\
\hline & 40 & 237563 & 239705 & 258067 & 260394 \\
\hline \multirow{5}{*}{$2.85 \% \mathrm{CNT}-5 \% \mathrm{CF}-\mathrm{RP}$} & 2 & 2.3182 & 2.3867 & 2.3135 & 2.3819 \\
\hline & 4 & 37.139 & 38.237 & 36.985 & 38.079 \\
\hline & 10 & 1443.9 & 1486.6 & 1436.6 & 1479.1 \\
\hline & 20 & 21522 & 22159 & 22531 & 23197 \\
\hline & 40 & 307511 & 316605 & 334053 & 343931 \\
\hline $4.75 \%$ CNT $-5 \%$ CF-RP & 2 & 2.8030 & 2.9279 & 2.7973 & 2.9219 \\
\hline & 4 & 44.906 & 46.907 & 44.720 & 46.713 \\
\hline & 10 & 1745.8 & 1823.6 & 1737.0 & 1814.4 \\
\hline & 20 & 26023 & 27183 & 27242 & 28456 \\
\hline & 40 & 371820 & 388390 & 403912 & 421912 \\
\hline $0.9 \%$ CNT $-10 \%$ CF-RP & 2 & 1.9893 & 2.0071 & 1.9852 & 2.0030 \\
\hline & 4 & 31.870 & 32.155 & 31.738 & 32.022 \\
\hline & 10 & 1239.0 & 1250.1 & 1232.8 & 1243.8 \\
\hline & 20 & 18469 & 18634 & 19334 & 19507 \\
\hline & 40 & 263881 & 266242 & 286657 & 289221 \\
\hline $2.7 \%$ CNT $-10 \%$ CF-RP & 2 & 2.5664 & 2.6415 & 2.5611 & 2.6361 \\
\hline & 4 & 41.115 & 42.319 & 40.945 & 42.144 \\
\hline & 10 & 1598.4 & 1645.3 & 1590.4 & 1636.9 \\
\hline & 20 & 23826 & 24524 & 24942 & 25673 \\
\hline & 40 & 340431 & 350399 & 369814 & 380642 \\
\hline 4.5\% CNT - $10 \%$ CF-RP & 2 & 3.0940 & 3.2291 & 3.0877 & 3.2225 \\
\hline & 4 & 49.568 & 51.733 & 49.363 & 51.519 \\
\hline & 10 & 1927.1 & 2011.2 & 1917.3 & 2001.1 \\
\hline & 20 & 28725 & 29979 & 30071 & 31384 \\
\hline & 40 & 410423 & 428348 & 445847 & 465318 \\
\hline
\end{tabular}


For example, for the square rod made of $(4.75 \% \mathrm{CNT}$ $+5 \% \mathrm{CF}+$ Polyimide) with a diameter of $40 \mathrm{~mm}$, the critical buckling load, considering the interphase, is calculated as $4 \%$ larger than that obtained without taking the interphase into consideration.

In addition, the comparison between the results generated based on the 3D brick model and 2D beam model indicates that the discrepancy between the predictions of two models can be neglected in the case of small values of radius/diameter. However, the difference increases as the radius/diameter gets larger.

\section{Conclusion}

A dual-step multi-scale FE procedure was employed in this work in order to investigate the buckling behavior of rods made of polyimide reinforced with the combination of CNT and CF. To this end, the elastic modulus and Poisson's ratio of CNT/CF-RP for various reinforcement types were first calculated. It was shown that the elastic modulus considerably increased when polyimide was reinforced by the combination of CNT and CF. Moreover, the effect of interphase on the results was examined. It was indicated that the elastic modulus obtained with considering the interphase effect was larger than that obtained without the interphase effect. It was also concluded that the effect of reinforcement on Poisson's ratio was insignificant. After determining the elastic properties of CNT/CF-RP, the critical buckling loads of hybrid polymer composite rods with circular and square crosssections were calculated. The results revealed that the buckling behavior of rods was significantly affected by the type of reinforcement. It was observed that there was a notable improvement in the resistance of rods to buckling when their material was a hybrid CNT/CFpolyimide composite instead of neat polyimide. A comparison was also made between the results of $3 \mathrm{D}$ brick and $2 \mathrm{D}$ beam models.

\section{References}

1. Bekyarova, E., Thostenson, E.T., Yu, A., Kim, H., Gao, J., Tang, J., Hahn, H. T., Chou, T.W., Itkis, M.E., and Haddon, R.C. "Multiscale carbon nanotubecarbon fiber reinforcement for advanced epoxy composites", Langmuir, 23, pp. 3970-3974 (2007).

2. Kepple, K.L., Sanborn, G.P., Lacasse, P.A., Gruenberg, K.M., and Ready, W.J. "Improved fracture toughness of carbon fiber composite functionalized with multi walled carbon nanotubes", Carbon, 46, pp. 2026-2033 (2008).

3. Sawi, I.E., Olivier, P.A., Demont, P., and Bougherara, H. "Processing and electrical characterization of a unidirectional CFRP compositefilled with double walled carbon nano-tubes", Compos. Sci. Technol., 73, pp. 19-26 (2012).
4. Tehrani, M., Safdari, M., Boroujeni, A.Y., Razavi, Z., Case, S.W., Dahmen, K., Garmestani, H., and Al-Haik, M.S. "Hybrid carbon fiber/carbon nanotube composites for structural damping applications", Nanotechnology, 24, p. 155704 (2013).

5. Alipour Skandani, A. and Al-Haik, M. "Viscoplastic characterization and modeling of hybrid carbon fiber/carbon nanotubes reinforced composites", Compos. Part B, 99, pp. 63-74 (2016).

6. Pal, G. and Kumar, S. "Multiscale modeling of effective electrical conductivity of short carbon fiber-carbon nanotube-polymer matrix hybrid composites", Mater. Des., 89, pp. 129-136 (2016).

7. Zhou, H.W., Mishnaevsky Jr., L., Yi, H.Y., Liu, Y.Q., Hua, X., Warrier, A., and Dai, G.M. "Carbon fiber/carbon nanotube reinforced hierarchical composites: Effect of CNT distribution on shearing strength", Compos. Part B, 88, pp. 201-211 (2016).

8. Mittal, G., Dhand, V., Rhee, K.Y., Park, S.-J., and Lee, W.R. "A review on carbon nanotubes and graphene as fillers in reinforced polymer nanocomposites", J. Indust. Eng. Chem., 21, pp. 11-25 (2015).

9. Seidel, G.D. and Lagoudas, D.C. "Micromechanical analysis of the effective elastic properties of carbon nanotube reinforced composites", Mech. Mater., 38, pp. 884-907 (2006).

10. Giannopoulos, G.I., Georgantzinos, S.K., and Anifantis, N.K. "A semi-continuum finite element approach to evaluate the young's modulus of single-walled carbon nanotube reinforced composites", Compos. Part B, 41, pp. 594-601 (2010).

11. Loos, M.R. and Manas-Zloczower, I. "Micromechanical models for carbon nanotube and cellulose nanowhisker reinforced composites", Polymer Eng. Sci., 53, pp. 882-887 (2013).

12. Ansari, R. and Hassanzadeh Aghdam, M.K. "Micromechanics-based viscoelastic analysis of carbon nanotube-reinforced composites subjected to uniaxial and biaxial loading", Compos. Part B, 90, pp. 512-522 (2016).

13. Ansari, R. and Hassanzadeh Aghdam, M.K. "Micromechanical characterizing elastic, thermoelastic and viscoelastic properties of functionally graded carbon nanotube reinforced polymer nanocomposites", Meccanica, 52, pp. 1625-1640 (2017).

14. Alva, A., Bhagat, A., and Raja, S. "Effective moduli evaluation of carbon nanotube reinforced polymers using micromechanics", Mech. Adv. Mater. Struct., 22, pp. 819-828 (2015).

15. Ansari, R., Hassanzadeh Aghdam, M.K., and Mahmoodi, M.J. "Three-dimensional micromechanical analysis of the CNT waviness influence on the mechanical properties of polymer nanocomposites", Acta Mech., 227, pp. 3475-3495 (2016).

16. Wattanasakulpong, N. and Ungbhakorn, V. "Analytical solutions for bending, buckling and vibration responses of carbon nanotube-reinforced composite 
beams resting on elastic foundation", Comput. Mater. Sci., 71, pp. 201-208 (2013).

17. Lin, F. and Xiang, Y. "Vibration analysis of carbon nanotube reinforced composite plates", Appl. Mech. Mater., 553, pp. 681-686 (2014).

18. Abdollahzadeh Shahrbabaki, E. and Alibeigloo, A. "Three-dimensional free vibration of carbon nanotubereinforced composite plates with various boundary conditions using Ritz method", Compos. Struct., 111, pp. 362-370 (2014).

19. Ansari, R., Faghih Shojaei, M., Mohammadi, V., and Sadeghi, F. "Nonlinear forced vibration analysis of functionally graded carbon nanotube-reinforced composite Timoshenko beams", Compos. Struct., 113, pp. 316-327 (2014).

20. Ansari, R., Hasrati, E., Faghih Shojaei, M., Gholami, R., and Shahabodini, A. "Forced vibration analysis of functionally graded carbon nanotube-reinforced composite plates using a numerical strategy", Physica E, 69, pp. 294-305 (2015).

21. Wu, H.L., Yang, J., and Kitipornchai, S. "Imperfection sensitivity of postbuckling behaviour of functionally graded carbon nanotube-reinforced composite beams", Thin-Walled Struct., 108, pp. 225-233 (2016).

22. Ansari, R., Shahabodini, A., and Faghih Shojaei, M. "Vibrational analysis of carbon nanotube-reinforced composite quadrilateral plates subjected to thermal environments using a weak formulation of elasticity", Compos. Struct., 139, pp. 167-187 (2016).

23. Mirzaei, M. and Kiani, Y. "Free vibration of functionally graded carbon-nanotube-reinforced composite plates with cutout", Beilstein J. Nanotechnol., 7, pp. 511-523 (2016).

24. Ansari, R., Pourashraf, T., Gholami, R., and Shahabodini, A. "Analytical solution for nonlinear postbuckling of functionally graded carbon nanotube-reinforced composite shells with piezoelectric layers", Compos. Part B, 90, pp. 267-277 (2016).

25. Ghorbani Shenas, A., Malekzadeh, P., and Ziaee, S. "Vibration analysis of pre-twisted functionally graded carbon nanotube reinforced composite beams in thermal environment", Compos. Struct., 162, pp. 325-340 (2017).

26. Gholami, R., Ansari, R., and Gholami, Y. "Nonlinear resonant dynamics of geometrically imperfect higher-order shear deformable functionally graded carbon-nanotube reinforced composite beams", Compos. Struct., 174, pp. 45-58 (2017).

27. Gholami, R. and Ansari, R. "The effect of initial geometric imperfection on the nonlinear resonance of functionally graded carbon nanotube-reinforced composite rectangular plates", Appl. Math. Mech., 39, pp. 1219-1238 (2018).

28. Gholami, R. and Ansari, R. "Nonlinear harmonically excited vibration of third-order shear deformable functionally graded graphene platelet-reinforced composite rectangular plates", Eng. Struct., 156, pp. 197-209 (2018).
29. Gholami, R. and Ansari, R. "Large deflection geometrically nonlinear analysis of functionally graded multilayer graphene platelet-reinforced polymer composite rectangular plates", Compos. Struct., 180, pp. 760 771 (2018).

30. Gholami, R., Ansari, R., and Gholami, Y. "Numerical study on the nonlinear resonant dynamics of carbon nanotube/fiber/polymer multiscale laminated composite rectangular plates with various boundary conditions", Aerosp. Sci. Technol., 78, pp. 118-129 (2018).

31. Gholami, R. and Ansari, R. "Nonlinear bending of third-order shear deformable carbon nanotube/fiber/polymer multiscale laminated composite rectangular plates with different edge supports", Eur. Phys. J. Plus, 133, p. 282 (2018).

32. Gholami, R. and Ansari, R. "Geometrically nonlinear resonance of higher-order shear deformable functionally graded carbon-nanotube-reinforced composite annular sector plates excited by harmonic transverse loading", Eur. Phys. J. Plus, 133, p. 56 (2018).

33. Odegard, G.M., Gates, T.S., Wise, K.E., Park, C., and Siochi, E.J. "Constitutive modeling of nanotubereinforced polymer composites", Compos. Sci. Technol., 63, pp. 1671-1687 (2003).

34. Tsai, J.L., Tzeng, S.H., and Chiu, Y.T. "Characterizing elastic properties of carbon nanotubes/polyimide nanocomposites using multi-scale simulation", Compos. Part B, 41, pp. 106-115 (2010).

35. Shokrieh, M.M. and Rafiee, R. "Stochastic multiscale modeling of CNT/polymer composites", Comput. Mater. Sci., 50, pp. 437-446 (2010).

36. Joshi, U.A., Sharma, S.C., and Harsha, S.P. "A multiscale approach for estimating the chirality effects in carbon nanotube reinforced composites", Physica E, 45, pp. 28-35 (2012).

37. Vu-Bac, N., Rafiee, R., Zhuang, X., Lahmer, T., and Rabczuk, T. "Uncertainty quantification for multiscale modeling of polymer nanocomposites with correlated parameters", Compos. Part B, 68, pp. 446-464 (2015).

38. Ahmadi, M., Ansari, R., and Rouhi, H. "Multi-scale bending, buckling and vibration analyses of carbon fiber/carbon nanotube-reinforced polymer nanocomposite plates with various shapes", Physica E, 93, pp. 17-25 (2017).

39. Ahmadi, M., Ansari, R., and Hassanzadeh-Aghdam, M.K. "Low velocity impact analysis of beams made of short carbon fiber/carbon nanotube-polymer composite: A hierarchical finite element approach", Mech. Adv. Mater. Struct., 26(13), pp. 1104-1114 (2019). https://doi.org/10.1080/15376494.2018.1430276

40. Ahmadi, M., Ansari, R., and Rouhi, H. "Free and forced vibration analysis of rectangular/ circular/annular plates made of carbon fiber-carbon nanotube-polymer hybrid composites", Sci. Eng. Compos. Mater., 26(1), pp. 70-76 (2019). https://doi.org/10.1515/secm-2017-0279 
41. Ahmadi, M., Ansari, R., and Rouhi, H. "On the free vibrations of piezoelectric carbon nanotubereinforced microbeams: a multiscale finite element approach", Iranian J. Sci. Technol. Trans. Mech. Eng., 43(Supplement 1), pp. 285-294 (2019). https://doi.org/10.1007/s40997-018-0157-x

42. Ahmadi, M., Ansari, R., and Rouhi, S. "Fracture behavior of the carbon nanotube/carbon fiber/polymer multiscale composites under bending test - A stochastic finite element method", Mech. Adv. Mater. Struct., 26(13), pp. 1169-1177 (2019). https://doi.org/10.1080/15376494.2018.1432790

43. Ahmadi, M., Ansari, R., and Rouhi, H. "Free vibration analysis of carbon fiber-carbon nanotube-polymer matrix composite plates by a finite element-based multiscale modeling approach", J. Multiscale Model., 9, p. 1850002 (2018).

44. Civalek, Ö. and Demir, Ç. "A simple mathematical model of microtubules surrounded by an elastic matrix by nonlocal finite element method", Appl. Math. Comput., 289, pp. 335-352 (2016).

45. Mercan, K. and Civalek, Ö. "DSC method for buckling analysis of boron nitride nanotube (BNNT) surrounded by an elastic matrix", Compos. Struct., 143, pp. 300-309 (2016).

46. Refaeinejad, V., Rahmani, O., and Hosseini, S.A.H. "An analytical solution for bending, buckling, and free vibration of FG nanobeam lying on Winkler-Pasternak elastic foundation using different nonlocal higher order shear deformation beam theories", Scientia Iranica, F, 24, pp. 1635-1653 (2017).

47. Norouzzadeh, A., Ansari, R., and Rouhi, H. "Isogeometric vibration analysis of small-scale Timoshenko beams based on the most comprehensive sizedependent theory", Scientia Iranica, F, 25, pp. 18641878 (2018).

48. Akgöz, B. and Civalek, Ö. "Buckling analysis of cantilever carbon nanotubes using the strain gradient elasticity and modified couple stress theories", $J$. Comput. Theor. Nanosci., 8, pp. 1821-1827 (2011).

49. Chen, W.J. and Li, X.P. "Size-dependent free vibration analysis of composite laminated Timoshenko beam based on new modified couple stress theory", Arch. Appl. Mech., 83, pp. 431-444 (2013).

50. Akgoz, B. and Civalek, Ö. "Bending analysis of embedded carbon nanotubes resting on an elastic foundation using strain gradient theory", Acta Astronautica, 119, pp. 1-12 (2016).

51. Karimzadeh, A. and Ahmadian, M.T. "Vibrational characteristics of size dependent vibrating ring gyroscope", Scientia Iranica, B (2018). DOI: 10.24200/SCI.2018.20495

52. Jafari-Talookolaei, R.-A., Ebrahimzade, N., RashidiJuybari, S., and Teimoori, K. "Bending and vibration analysis of delaminated Bernoulli-Euler microbeams using the modified couple stress", Scientia Iranica, B, 25, pp. 675-688 (2018).

53. Shen, L. and Li, J. "Transversely isotropic elastic properties of single-walled carbon nanotubes", Phys. Rev. B, 69, p. 045414 (2004).

54. Shen, L. and Li, J. "Transversely isotropic elastic properties of multiwalled carbon nanotubes", Phys. Rev. B, 71, p. 035412 (2005).

55. Selmi, A., Friebel, C., Doghri, I., and Hassis, H. "Prediction of the elastic properties of single walled carbon nanotube reinforced polymers: A comparative study of several micromechanical models", Compos. Sci. Technol., 67, pp. 2071-2084 (2007).

56. Kulkarni, M., Carnahan, D., Kulkarni, K., Qian, D., and Abot, J.L. "Elastic response of a carbon nanotube fiber reinforced polymeric composite: A numerical and experimental study", Compos. Part B, 41, pp. 414-421 (2010).

57. Odegard, G.M., Clancy, T.C., and Gates, T.S. "Modeling of the mechanical properties of nanoparticle/polymer composites", Polymer, 46, pp. 553-562 $(2005)$.

\section{Biographies}

Masoud Ahmadi received his BSc and MSc degrees in Mechanical Engineering in 2013 and 2016, respectively, from the Razi University and University of Guilan, Iran. His research interests include finite element analysis, structural analysis, and biomechanics.

Reza Ansari received his $\mathrm{PhD}$ degree in 2008 from the University of Guilan, Iran, where he is currently a faculty member at the Department of Mechanical Engineering. He was also a visiting fellow at Wollongong University, Australia from 2006-2007. He has authored numerous refereed journal papers and book chapters. His research interests include computational nano- and micro-mechanics, advanced numerical techniques, nonlinear analyses, and prediction of the mechanical behavior of smart composite/FGM shelltype structures.

Hessam Rouhi received his $\mathrm{PhD}$ degrees in Mechanical Engineering in 2016 from the University of Guilan, Iran. He is currently a faculty member at the Department of Engineering Science, Faculty of Technology and Engineering, East of Guilan, University of Guilan, Iran. His research interests include computational micro- and nano-mechanics and the mechanical behavior of structures including buckling and vibration. 